\title{
Urgent-Start Peritoneal Dialysis: The First Year of Brazilian Experience
}

\author{
Dayana Bitencourt Dias Marcela Lara Mendes Vanessa Burgugi Banin \\ Pasqual Barretti Daniela Ponce
}

São Paulo State University - UNESP, Alameda dasHortencias, Botucatu, Brazil

\section{Keywords}

Urgent-start peritoneal dialysis - Acute peritoneal dialysis . Unplanned peritoneal dialysis · Urgent-start dialysis

\begin{abstract}
Background: This study aimed to evaluate mechanical and infectious complications associated with urgent-start peritoneal dialysis (PD) and patients and technique survival in the first 180 days. Methods: It was a prospective study that evaluated chronic patients who started unplanned PD using high-volume PD (HVPD) right after ( $<72$ h) PD catheter placement. After hospital discharge, patients were treated with intermittent PD on alternate days in a dialysis unit until family training was provided. Results: Fifty-one patients fulfilling the following criteria were included: age was $62.1 \pm 15$ years, with diabetes as the main etiology of end-stage renal disease (39\%), and uremia as the main dialysis indication (76\%). Metabolic and fluid controls were achieved after 3 sessions of HVPD, and patients remained in intermittent PD for $23.2 \pm 7.2$ days. Mechanical complications occurred in $25.7 \%$ and peritonitis rate was 0.5 episode/patient-year. In the first 6 months, technique and patients survival rates were 86 and $82.4 \%$ respectively. Conclusion: The PD modality was a feasible and safe alternative to hemodialysis in the urgentstart dialysis.

(c) 2017 S. Karger AG, Basel
\end{abstract}

\section{Introduction}

Starting dialysis in an unplanned manner is a common occurrence even for patients with nephrology follow-up [1]. Over $50 \%$ of patients who initiated hemodialysis (HD) started using central venous catheter (CVC) in Denmark, while in the United States, Canada and Brazil, more than $80 \%$ started using CVC $[1,2]$. This situation is considered suboptimal because $\mathrm{CVC}$ is independently associated with increased mortality and high rates of bacteremia $[2,3]$. An alternative approach to manage these patients is to start them on peritoneal dialysis (PD).

Few studies have described patients' experience with urgent-start PD [4-8]. Some reports have compared urgent-start HD to PD and found that urgent-start PD is a safe and effective alternative to HD for unplanned dialysis starts $[4,5]$.

To date, none of the urgent-start PD studies have described a program that uses only percutaneous PD catheter insertion performed by nephrologists and includes patients that started PD early (within $72 \mathrm{~h}$ of catheter insertion), using a high volume of dialysate. In this report, we review the first year of a Brazilian program of urgentstart PD and our aims were to determine mechanical and infectious complications, and to evaluate patients and technique survival in the first 180 days.

\section{KARGER}

(c) 2017 S. Karger AG, Basel

E-Mail karger@karger.com

www.karger.com/bpu
Dayana Bitencourt Dias

São Paulo State University - UNESP

Alameda dasHortencias

823 Botucatu, SP (Brazil)

E-Mail dponce@fmb.unesp.br 


\section{Methodology}

\section{Patients}

Between July 2014 and July 2015, all CKD patients who were hospitalized, diagnosed with end-stage renal disease (ESRD), and started on unplanned urgent PD at the Botucatu Medical School, Sao Paulo, Brazil, were recruited. ESRD was defined on the basis of KDOQI Clinical Practice Guidelines for Chronic Kidney Disease [9].

The urgent dialysis indications were uremia, fluid overload, hyperkalemia $(\mathrm{K}>6.5 \mathrm{mEq} / \mathrm{L})$, and acid-base disorders (bicarbonate $<10 \mathrm{mEq} / \mathrm{L}$ ) refractory to clinical measures. Uremia was defined as blood urea nitrogen above $70.0 \mathrm{mg} / \mathrm{dL}$ and the presence of symptoms such as nausea, vomiting, weight loss, inappetence, and consciousness alteration, secondary to the retention of nitrogenous toxins $[10,11]$. Unplanned PD was defined as initiation in less than $72 \mathrm{~h}$ after the implantation of the peritoneal catheter, without family training or adequacy of the home [12]. Exclusion criteria were prior history of dialysis, multiple organ failure, coma, and absolute contraindication to the PD method. The absolute contraindication to the PD method was the presence of recent abdominal surgery ( $<30$ days); multiple previous abdominal surgery (more than 2 ); severe respiratory insufficiency ( $\mathrm{FiO} 2>70 \%$ ); abdominal infections; severe hyperkalemia with characteristic changes in electrocardiogram (prolonged QRS or bradycardia); and acute pulmonary edema [10-13]. These patients were treated with unplanned HD.

The implant of Tenckhoff catheter was held through the percutaneous Seldinger technique by nephrology team [13]. Highvolume PD (HVPD) was previously defined by our group as sessions lasting $24 \mathrm{~h}$, with a prescribed $\mathrm{Kt} / \mathrm{V}$ of 0.5 , using large volume of dialysate $(30 \mathrm{~mL} / \mathrm{kg})$, a cycler and flexible catheter $[11,12]$. It was used during the first 3 days of PD in order to achieve metabolic and fluid control. PD solution was Dianeal ${ }^{\circledR}$, manufactured by Baxter International Inc. (Illinois, IL, USA; $\mathrm{Na}=132 \mathrm{mEq} / \mathrm{L}$, $\mathrm{Ca}=3.5 \mathrm{mEq} / \mathrm{L}, \mathrm{K}=0 \mathrm{mEq} / \mathrm{L}, \mathrm{Mg}=1.5 \mathrm{mEq} / \mathrm{L}$, lactate $=40 \mathrm{mEq} / \mathrm{L}$, $1.5-4.25 \%$ glucose) and PD was performed using Home Choice cycler.

After metabolic and fluid controls were achieved, patients had hospital discharge. blood urea nitrogen lower than $50 \mathrm{mg} / \mathrm{dL}$, potassium $<5.0 \mathrm{mEq} / \mathrm{L}$, bicarbonate $>20 \mathrm{mEq} / \mathrm{L}$, and absence of symptoms of uremia or hypervolemia [12] were considered adequate metabolic control.

After hospital discharge, patients were treated with intermittent PD at the dialysis unit; sessions lasted between 8 and $11 \mathrm{~h} \mathrm{ac}$ cording to laboratory tests and clinical parameters until their family had been trained and their homes were prepared to accommodate them. Laboratorial exams were performed weekly. PD was assisted by nephrologist nurses.

The basic ethical principles for research involving human beings were followed, and this study was approved by the Ethics Committee of the Botucatu Medical School in June/2014 (IRB approval number 0641/014). Written informed consent was obtained from all patients or relatives prior to their inclusion in the study. It was also registered in Clinical Trials (NCT 02646436)

\section{Follow-Up of Unplanned PD Patients}

Each patient was followed up at risk for 180 days after starting dialysis. Mechanical complications included tip catheter migration, catheter obstruction, and dialysate leakage, while infectious complications included exit site infections (ESI) and peritonitis [14]. Patients were followed up by the same research team from the time of the peritoneal catheter implantation until the protocol interruption (death, transplantation, recovery of renal function or switch to HD due to mechanical or infectious complications). Death was censored for technique survival evaluation.

\section{Statistical Analysis}

It was performed using the statistical program Sigma Stata for Windows (version 4.0, 2016). Initially, descriptive analysis was done and measures of central tendency and dispersion for continuous variables and frequencies for categorical variables were calculated. Kaplan-Meier was performed for patients and technique-survival curves.

\section{Results}

During the study period (from July 2014 to July 2015), 113 patients started dialysis in our center: 51 unplanned PD (45.1\%), 49 unplanned HD (43.4\%), 6 planned PD (5.3\%), and 7 planned HD (6.2\%). Among the patients in urgent-start PD, age was $62.1 \pm 15$ years, diabetes was the main etiology of CKD (39\%), and uremia was the main dialysis indication (76\%). All insertions were done percutaneously by the nephrology team. Dialysis was initiated within $72 \mathrm{~h}$ in all patients (range 0-3 days, median: 2 days).

Adequate metabolic control was achieved after 3 sessions of PD (Table 1), and patients remained in intermittent $\mathrm{PD}$ for $23.2 \pm 7.2$ days receiving $11.5 \pm 3.1$ IPD sessions. Mechanical complications occurred in $25.7 \%$. The main mechanical complications were catheter tip migration (8 patients $-15.6 \%$ ) and leakage (4 patients $-7.8 \%$ ). Four patients had a minor peri-catheter leakage of dialysate, which were managed by stopping the treatment for $24 \mathrm{~h}$ and restarting with a lower infusion volume (from 2 to $1.5 \mathrm{~L}$ ). There was no need for catheter replacement due to leakage and no patient changed the dialysis method for this reason. After 5 days, we infused 2 L per cycle again. ESI occurred in $17 \%$ of patients and peritonitis rate was 0.5 episode/patient-year (Table 2 ).

In the first 180 days, technique and patient survival rates were 86 and $82.4 \%$ respectively (Fig. $1 \mathrm{a}, \mathrm{b}$ ). The main causes of death were cardiovascular event (22.3\%) and septic shock (55.5\%, mainly pulmonary site). There were no deaths associated with catheter implantation or PD therapy directly. The causes of making a change to HD were mechanical complications (5 patients), peritonitis (4 patients), hydrothorax (1 patient), and psychosocial reasons (1 patient). Recovery of renal function occurred in 3 patients (5.8\%). Patients with recovery of re- 
Table 1. Metabolic control of patients treated with PD urgent start

\begin{tabular}{|c|c|c|c|c|}
\hline & \multicolumn{4}{|l|}{ Sessions of HVPD } \\
\hline & pre PD & after 1 st session & after 2 nd session & after 3rd session \\
\hline Creatinine, $\mathrm{mg} / \mathrm{dL}$ & $8.3 \pm 3.5$ & $7.3 \pm 3.4$ & $7.5 \pm 3.4$ & $7.4 \pm 3.4$ \\
\hline $\mathrm{BUN}, \mathrm{mg} / \mathrm{dL}$ & $86.8 \pm 28.9$ & $66.9 \pm 21.7$ & $59.7 \pm 18.1$ & $50.7 \pm 16.7$ \\
\hline Potassium, $\mathrm{mEq} / \mathrm{L}$ & $4.7 \pm 0.8$ & $4.3 \pm 0.75$ & $4.4 \pm 0.7$ & $4.4 \pm 0.5$ \\
\hline Bicarbonate, mEq/L & $18 \pm 4.3$ & $20.3 \pm 3.1$ & $21.6 \pm 3.3$ & $22.4 \pm 2.9$ \\
\hline PD prescription & $\operatorname{HVPD}(\mathrm{Kt} / \mathrm{V}=0.5)$ & $\mathrm{HVPD}(\mathrm{Kt} / \mathrm{V}=0.5)$ & $\operatorname{HVPD}(\mathrm{Kt} / \mathrm{V}=0.5)$ & $\mathrm{HVPD}(\mathrm{Kt} / \mathrm{V}=0.5)$ \\
\hline
\end{tabular}

$\mathrm{PD}$, peritoneal dialysis; HVPD, high-volume peritoneal dialysis; BUN, blood urea nitrogen.

nal function are under pre-dialytic follow-up. Two patients underwent kidney transplant.

There were 24 patients in the Chronic PD Program before unplanned PD was started. During this study, 3 patients of the planned PD group died, 4 changed to HD due to infectious complications, one underwent kidney transplantation, and 3 initiated planned PD. Therefore, 1 year after the initiation of this urgent-start PD program (from July 2014 to July 2015), the size of our PD program grew from 24 to 46 patients (91.7\%).

\section{Discussion}

Most patients with end-stage CKD start unplanned RRT, which is associated with reduced survival, especially in the first 90 days of therapy $[2-5,10,14,15]$. Urgentstart PD can be a welcome alternative to $\mathrm{HD}$ via CVC for uremic or fluid overloaded patients requiring the unplanned initiation of dialysis [2-7].

We have offered PD as an urgent-start method for CKD patients since July 2014 and have performed a prospective study that aims to evaluate the mortality rate in patients who started unplanned urgent $P D$ in the first 180 days. HVPD was initiated right after $(<72 \mathrm{~h})$ PD catheter placement by the nephrologist team using the Seldinger technique, and it was kept until metabolic and fluid controls were achieved. After hospital discharge, patients were treated with intermittent PD on alternate days or daily at the dialysis unit until family training. We found the strategy to be feasible and safe. The complication rate in our patients was low and agreed with that of previous reports in this field.

During the study period, 113 patients started dialysis in our center: $45.1 \%$ unplanned PD, 43.4\% unplanned HD, and only $11.5 \%$ in planned methods (PD or HD). It result-
Table 2. Clinical characteristics, complications, and outcome of patients treated with unplanned peritoneal dialysis

\begin{tabular}{|c|c|}
\hline Clinical characteristics & $n=51$ \\
\hline Age, years & $62.1 \pm 15$ \\
\hline Gender, male, $n(\%)$ & $27(52.9)$ \\
\hline Two or more comorbid conditions & $24(47.0)$ \\
\hline \multicolumn{2}{|l|}{ Etiology of CKD, $n(\%)$} \\
\hline Diabetes & $20(39)$ \\
\hline Hypertension & $7(14)$ \\
\hline Glomerulonephritis & $9(18)$ \\
\hline Obstructive & $4(8)$ \\
\hline Others & $11(21)$ \\
\hline \multicolumn{2}{|l|}{ Dialysis indication, $n(\%)$} \\
\hline Úremia & $39(76)$ \\
\hline Fluid overload & $6(12)$ \\
\hline Anuria & $5(10)$ \\
\hline Refractory heart failure & $1(2)$ \\
\hline \multicolumn{2}{|l|}{ Complications } \\
\hline \multicolumn{2}{|l|}{ Infectious complications } \\
\hline Exit site infection, $n(\%)$ & $9(17)$ \\
\hline Peritonitis (episode/patient/year) & 0.5 \\
\hline \multicolumn{2}{|l|}{ Mechanical complications, $n(\%)$} \\
\hline Catheter tip migration with & \\
\hline surgical replacement & $8(15.6)$ \\
\hline Leakage along PD catheter & $4(7.8)$ \\
\hline Pleural leakage & $1(1.9)$ \\
\hline Abdominal pain & $1(1.9)$ \\
\hline PD patient survival in 180 days, $n(\%)$ & $42(82.4)$ \\
\hline PD technique survival in 180 days, $n(\%)$ & $44(86.3)$ \\
\hline
\end{tabular}

ed in chronic PD program growth at $91.7 \%$ after 12 months. We strongly believe that combining the program for unplanned start on PD with a program for nurse-assisted PD dramatically increases the number of patients who can be given a real choice of a home-based dialysis modality. 


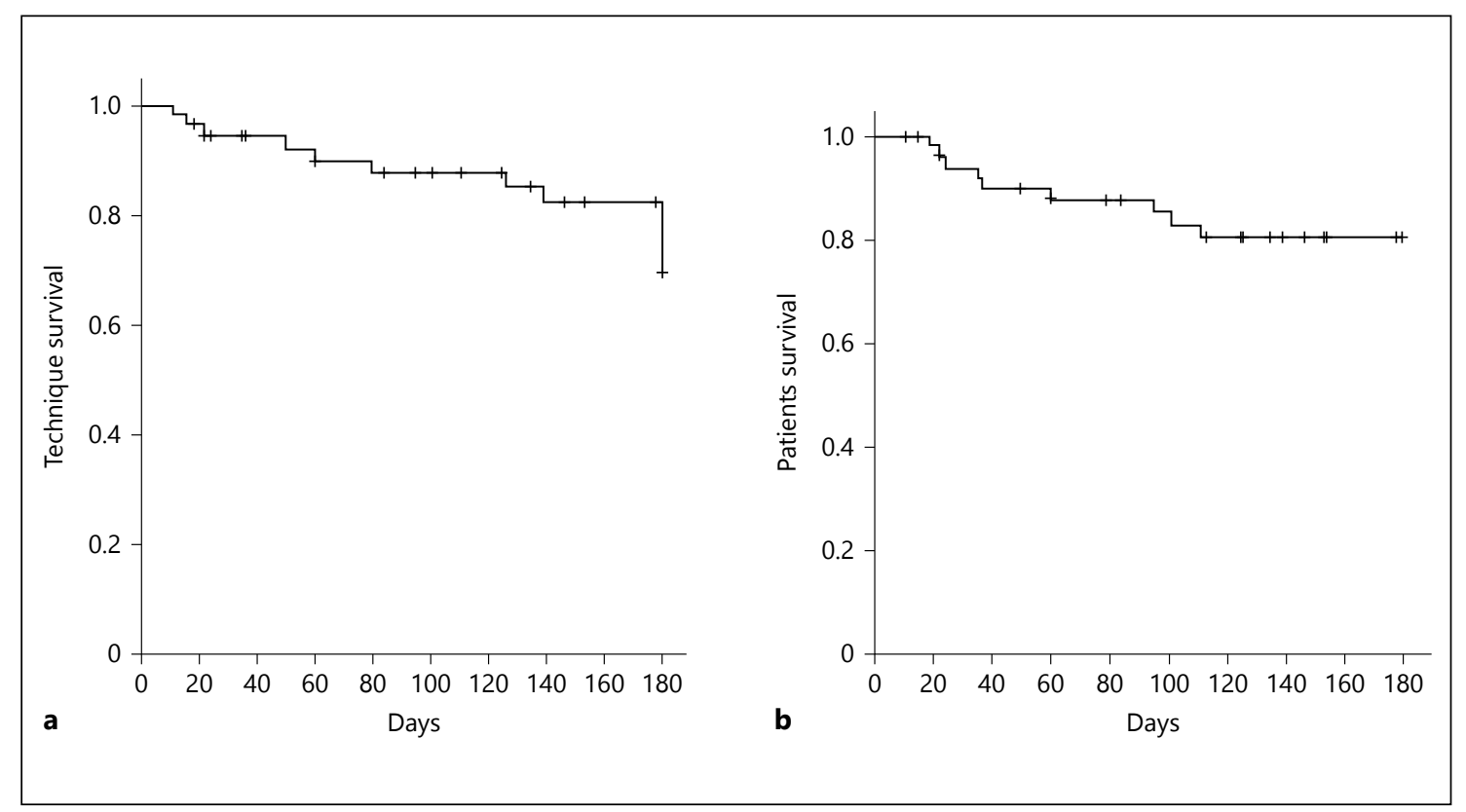

Fig. 1. a, b Technique and patients survival of those undergoing urgent-start peritoneal dialysis.

Metabolic and fluid controls were achieved after 3 sessions of HVPD, and patients remained in intermittent PD for 3 weeks. Concerning infectious and mechanical complications, our results were similar to those reported in the literature.

Seven previous studies assessed the risk of catheter dysfunction in urgent-start PD $[1,4-7,10,16]$ and the rate of risk ranged from 1.9 to $33.3 \%$. These studies also assessed the rate of PD-related infections. The duration of assessment ranged from 1 to 6 months and peritonitis occurred in $2.4-15.4 \%$ and ESI ranged from 1.3 to $11 \%$.

Ivarsen and Povlsen [1], Povlsen et al. [8] and Liu et al. [16] showed that total mechanical complications occurred significantly more in urgent-start than conventional start PD $[1,8,16]$. They noted that there was an increased need for surgical replacement of PD catheter in the urgent group. We noted a high rate of catheter dysfunction due to migration in our urgent-start patients (25.7\%). We believe that this is because an early start gives us little time to wait for the catheter to migrate spontaneously. However, in those studies, the technique failure was similar between urgent and conventional start PD. In our study, the rate of technique survival was $86 \%$ at 180 days. Povlsen et al. [8] and Ivarsen and Povlsen [1] looked at technique survival at 3 months in their urgent start PD group and it was 86.7 vs. $90 \%$, respectively $[8,1]$. Song et al. [17] showed that catheter survival at 1 year was about $85 \%$.

Patient survival rate was $82.4 \%$ at 180 days. Five studies assessed survival $[1,4-6,10]$. Lobbedez et al. [5] compared urgent-start HD with urgent-start PD and found the patients survival at 1 year was $79 \%$ on HD compared with $83 \%$ on PD. Koch et al. [4] compared the survival rates in urgent-start $\mathrm{HD}$ vs. urgent-start $\mathrm{PD}$ patients. There was no significant difference in mortality at 6 months between the 2 groups (30.3\% for PD and $42.1 \%$ for $\mathrm{HD} ; p=0.19$ ).

Our study has some limitations. This is a single-center, nonrandomized study with a relatively small sample size and no control group, making it difficult to generalize our results to other centers. Finally, we did not compare clinical characteristics and outcome between patients treated with unplanned PD vs. unplanned HD or unplanned PD vs. planned PD. However, we have been performing others studies that had this as their aim.

Despite these limitations, to the best of our knowledge, this is the first study that has assessed the efficiency urgent-start PD in a developing country. PD catheter insertions were performed only by nephrologists using the Seldinger technique and included patients who started PD early (within $72 \mathrm{~h}$ of catheter insertion), using a high volume of dialysate. We have seen a growth of $91 \%$ in our PD program since introducing this initia- 
tive and this growth can have significant economic advantages. We emphasize that the success of our urgentstart PD program was due to several factors. First, there was the interventional nephrologist team that was able to insert PD catheter at short notice. Second, there was the PD nursing team who were prepared to perform PD and to train the patients and their families within a short time and this can result in the disruption of previous elective PD training and other PD unit activities. Third, there was a coordinating person who made everything happen in a timely manner and this can be a very demanding task. Lastly, this approach required commitment from the patients and their family members. It followed that for all these initiatives to work well, there had to be commitment from both administrative and physician leadership within the renal program concerned.

Our observations suggest that the PD modality may be a feasible and safe alternative to HD, not only in planned cases but also in the unplanned setting. Moreover, the concept of urgent start to chronic PD may be a tool to increase the $\mathrm{PD}$ penetration rate among incident patients initiating chronic dialysis therapy. In conclusion, unplanned PD is an option and should be offered in an unbiased way to all patients without contraindications to starting urgent PD.

\section{Ethical Statement}

D.P. received International Research Grant from Baxter Healthcare in 2015.

The basic ethical principles for research involving human beings were followed, and this study was approved by the Ethics Committee of the Botucatu Medical School in June/2014 (IRB approval number 0641/014). It was also registered in Clinical Trials (NCT 02646436).

Informed consent was obtained from all individual participants included in the study.

\section{Disclosure Statement}

The other authors have declared no competing interest.

\section{Author Contributions}

D.B.D. and D.P.: made substantial contributions to the conception and design of the study, acquisition of data, initiation and completion of analysis and interpretation of data. M.L.M. and V.B.B.: were involved in the acquisition of data and drafting the manuscript. D.P. and P.B.: revised the documentation critically for ensuring the inclusion of important intellectual content. D.B.D. and D.P.: gave final approval of the version to be published. All authors agreed to be accountable for all aspects of the work in ensuring that questions related to the accuracy or integrity of any part of the work are appropriately investigated and resolved.

\section{References}

1 Ivarsen P, Povlsen JV: Can peritoneal dialysis be applied for unplanned initiation of chronic dialysis? Nephrol Dial Transplant 2014;29: 2201-2206.

2 Perl J, Wald R, McFarlane P, Bargman JM, Vonesh E, Na Y, Jassal SV, Moist L: Hemodialysis vascular access modifies the association between dialysis modality and survival. J Am Soc Nephrol 2011;22:1113-1121.

3 Panocchia N, Tazza L, Di Stasio E, Liberatori M, Vulpio C, Giungi S, Lucani G, Antocicco M, Bossola M: Mortality in hospitalized chronic kidney disease patients starting unplanned urgent haemodialysis. Nephrology 2016;21:62-67.

4 Koch M, Kohnle M, Trapp R, Haastert B, Rump LC, Aker S: Comparable outcome of acute unplanned peritoneal dialysis and haemodialysis. Nephrol Dial Transplant 2012;27: 375-380.

5 Lobbedez T, Lecouf A, Ficheux M, Henri P, Hurault de Ligny B, Ryckelynck JP: Is rapid initiation of peritoneal dialysis feasible in unplanned dialysis patients? A single-centre experience. Nephrol Dial Transplant 2008;23: 3290-3294.
6 Casaretto A, Rosario R, Kotzker WR, PaganRosario Y, Groenhoff C, Guest S: Urgent-start peritoneal dialysis: report from a U.S. private nephrology practice. Adv Perit Dial 2012;28: 102-105.

7 Alkatheeri AM, Blake PG, Gray D, Jain AK: Success of urgent-start peritoneal dialysis in a large Canadian renal program. Perit Dial Int 2016;36:171-176.

8 Povlsen JV, Sorensen AB, Ivarsen P: Unplanned start on peritoneal dialysis right after PD catheter implantation for older people with end-stage renal disease. Perit Dial Int 2015;35:622-624.

9 Kidney Disease Improving Global Outcomes (KDIGO): Clinical practice guideline for the evaluation and management of chronic kidney disease. Kidney Int Suppl 2013;3:S19-S75.

10 Dias DB, Banin V, Mendes ML, Barretti P, Ponce D: Peritoneal dialysis can be an option for unplanned chronic dialysis: initial results from a developing country. Urol and Nephrol Int 2016;48:901-906.

11 Gabriel DP, Nascimento GV, Caramori JT, Martim LC, Barretti P, Balbi AL: High volume peritoneal dialysis for acute renal failure. Perit Dial Int 2007;27:277-282.
12 Gabriel DP, Caramori JT, Martim LC, Barretti P, Balbi AL: High volume peritoneal dialysis vs daily hemodialysis: a randomized, controlled trial in patients with acute kidney injury. Kidney Int Suppl 2008;108:S87-S93.

13 Sirivongs D, Praderm L, Chan-On C: Experiences on bedside Tenckhoff catheter implantation. J Med Assoc Thai 2011;94(suppl 4): S58-S63.

14 Li PK, Szeto CC, Piraino B: ISPD peritonitis recommendations: 2016 update on prevention and treatment. Perit Dial Int 2016;36: 481-508.

15 Dias DB, Banin V, Mendes ML, Barretti P, Ponce D: Peritoneal dialysis as an option for unplanned initiation of chronic dialysis. Hemodial Int 2016;48:901-906.

16 Liu Y, Zhang L, Lin A, Ni Z, Qian J, Fang W: Impact of break-in period on the short-term outcomes of patients started on peritoneal dialysis. Perit Dial Int 2014;34:49-56.

17 Song JH, Kim GA, Lee SW, Kim MJ: Clinical outcomes of immediate full-volume exchange one year after peritoneal catheter implantation for CAPD. Perit Dial Int 2000;20:194199. 